\title{
Article \\ Involvement and Multi-Sectoral Collaboration: Applying Principles of Health Promotion during the Implementation of Local Policies and Measures-A Case Study
}

\author{
Monica Lillefjell * and Ruca Elisa Katrin Maass \\ Department of Neuromedicine and Movement Science, Norwegian University of Science and Technology, \\ 7047 Trondheim, Norway; ruca.e.maass@ntnu.no \\ * Correspondence: monica.lillefjell@ntnu.no
}

check for

updates

Citation: Lillefjell, M.; Maass, R.E.K. Involvement and Multi-Sectoral Collaboration: Applying Principles of Health Promotion during the Implementation of Local Policies and Measures-A Case Study. Societies 2022, 12, 5. https://doi.org/10.3390/ soc12010005

Academic Editors: Elisabeth Fosse and Marit Kristine Helgesen

Received: 2 November 2021

Accepted: 23 December 2021

Published: 25 December 2021

Publisher's Note: MDPI stays neutral with regard to jurisdictional claims in published maps and institutional affiliations.

Copyright: (C) 2021 by the authors. Licensee MDPI, Basel, Switzerland. This article is an open access article distributed under the terms and conditions of the Creative Commons Attribution (CC BY) license (https:// creativecommons.org/licenses/by/ $4.0 /)$.

\begin{abstract}
Five principles for health promotion (HP) stand out in various forms, providing guidance for HP measures and policy implementation: (1) a broad and positive health concept, (2) participation and involvement of key stakeholders, (3) build action and action competence by involving and empowering target groups, (4) a setting perspective, and (5) equity in health. The purpose of this study is to describe, and critically discuss, how the five HP principles can be applied to structure collaboration processes for implementing HP measures in local communities. A case study methodology was applied when investigating how the HP principles guided actions and focus-of-attention throughout the process of implementing a local community HP measure. Of special importance was the broad involvement of stakeholders and the anchoring of overarching, as well as specific, HP goals in the municipal strategic documents to ensure political commitment, ownership, and adequate resources. Direction on how to apply or achieve the HP principles should be further explored, described, and brought into systematic day-to-day work for a better society-development.
\end{abstract}

Keywords: HP principles; involvement; political commitment; multisectoral collaboration; implementation; local community measure

\section{Introduction}

Recognition of the importance of multi- and intersectoral approaches dates back as far as the Alma-Ata Declaration of 1978, where Article 4 called for the involvement of all related sectors in efforts to promote health [1]. In 1986, the Ottawa Charter put forward the concept of healthy public policy and called for the involvement of other sectors in health promotion (HP) [2]. More recently, Health 2020 highlights the importance of multi- and intersectoral action through whole system approaches, such as whole-ofgovernment, whole-of-society approaches and Health in all Policies (HiAP) [3-5]. The whole-of-government approach refers to "the diffusion of governance vertically across levels of government and arenas of governance and horizontally throughout sectors" [3]. The whole-of-society approach extends the sphere beyond the traditional governmental decision-making by calling for increased engagement of the private sector, civil society, communities, and individuals in health-related actions [3]. HiAP, a whole-system approach, aims to integrate health considerations into policies that lie outside the health sector $[4,5]$. International organizations, such as the World Health Organization (WHO), EU, OECD, and the World Bank have also proposed standards for good governance of public health and HP. At the core of health promotion is a commitment to a set of values related to equity, social justice, empowerment, and health as a human right [6,7]. Here, mechanisms that foster participation from citizens, high degree of accountability and transparency, and a dedication to reducing poverty and promoting health equity through multi-sectoral governance, are particularly emphasized $[2,8]$.

Health promotion is principle-driven $[6,7,9,10]$. Local HP policies and measures are highly complex, and therefore require complexity-oriented means of understanding, 
interpreting, and structuring the ways in which measures and policies are processed, managed, and implemented $[6,9]$. By reviewing the health promotion literature, there are, in addition to the principles of Health in All Policies [3-5], five principles for health promotion that stand out in various forms and provide guidance for HP measures and policy implementation [2,7,9-11]. The principles are derived from growing experience that highlight central challenges for health promotion and include [9]: (1) a broad and positive health concept, (2) participation and involvement of key stakeholders, (3) build action and action competence by involving and empowering target groups, (4) a setting perspective, and (5) equity in health.

Applying a broad, positive health concept is crucial for achieving a whole-of-government or even whole-of-society approach. A broad definition of health allows stakeholders to work towards common goals from various starting points and across settings [2,7,9-12]. Participation, in terms of involving different relevant settings and stakeholders in the implementation, is underscored as being particularly important for improving the transparency of decisions and the efficacy of HP actions. Participation contains both awareness of the assets that local people bring to solving complex problems and appreciation of the value and importance of genuine and systematic participation in generating, implementing, and reviewing solutions $[9,10,13-18]$. Being involved in decision making might thereby not only increase relevance of developed measures, but it can even contribute to empowerment for people in vulnerable situation directly by building action competence and facilitate for community action [12-15,19-21]. A setting approach [10,14,17-19], characterized by community participation, partnership, empowerment, and equity, offers, e.g., a conceptual framework for developing measures aimed at sustainable impacts in community health promotion. Last, involving people and social groups, especially in vulnerable situations, in local development, emerges as a key strategy to ensure that measures build on local resources and contribute to social equity [21].

While these principles are derived from experiences with developing and implementing HP interventions [9], less is known in terms of if, and how, they can contribute to inform approaches and structure collaboration processes during the planning and implementation of new measures.

The objective of the present article is to describe and critically discuss how the five above-presented HP principles can be applied to structure collaboration processes for implementing HP measures in local communities. In this context, we want to specifically explore:

$>$ How the principles can contribute to guide focus of attention and help to design approaches

$>$ How the principles can guide collaboration processes and help to define activities during development and implementation

$>$ How applying the principles can contribute to develop locally grounded measures that contribute to HP

To address these questions, we apply a case study methodology [22] to investigate how these five HP principles guided actions and focus-of-attention throughout the collaboration process of implementing a local green space recreation area, in the context of a municipality in Norway. An unused railway-line was developed into a universal designed path and areas for play, social interaction, and recreation. Available evaluations of the recreational area $[21,23,24]$ suggest that the area works in line with intentions to contribute to HP in the local context. It thereby emerges as a relevant case to unravel the potential benefits of, and barriers for, applying the HP principles to guide local actions.

\subsection{How Did We Operationalize the HP Principles?}

The above-described principles for health promotion define goals and recommend strategies for public health work. In order to apply the five HP principles in the context of implementing a local HP measure, we need to clarify our understandings of the concepts. 
The principle of a broad and positive health concept $[2,6,7,9,11,14]$ has contributed to developing the knowledge base on the relationship between sustainable development and health, as well as the strategies required to achieve this development. Moreover, the Ottawa Charter [2] emphasizes that a health-friendly and cross-sectoral policy is required to realize the intentions embedded in strategies, reforms, and legislation. As such, applying a broad and positive health concept, when implementing HP measures, implies commitment to a set of values related to equity, social justice, empowerment, and to health as a human right, as well as shaped strategies and activities across sectors $[6,7,9,16,24,25]$

Participation and involvement of stakeholders can happen at various levels and with various impact on ongoing processes [26]. It is also closely linked to the principle of building action capacity through the involvement of target groups, as both principles center around involving people in the processes linked to planning and implementing measures that are relevant for them $[21,23,24,27,28]$. As such, applying these principles implies multilevel involvement and participation of stakeholders and target groups during the implementation process.

$A$ "setting" is defined as a systemic whole, and the focus is on how the different parts of the setting are related to and affect each other [9,10,17-19]. Applying a setting-perspective, such as, in this case, the process of implementing a local recreational area, thereby implies viewing the municipality as a setting, in which different parts, institutions, and processes affect each other and can cause changes within and across their internal boundaries [17-19]. Moreover, as settings are partly defined by their boundaries, internal rules and values, available resources and external conditions, local plans, and strategic documents, as well as legal rights and responsibilities that lie within the municipal setting were central elements that should be considered.

Health equity has been thoroughly established as an important goal and central strategy for health promotion; it is also anchored in the Norwegian Public Health Act [29].

Safeguarding a health equity perspective, when implementing a local recreation area, implies defining people with low SES and below-average health-outcomes as a main target group and to apply inclusive processes with respect to channels- and methods-ofinvolvement $[21,24,25,28]$. It also implies a need to keep close track of potential benefits and hazards for people in vulnerable situations before conducting each step-of-implementation.

\section{Methodology}

Case study is an ideal methodology when a holistic, in-depth investigation is needed to understand real life activities and processes [22]. In the following, we present an explanatory case study centering on the implementation process of a local community recreational green space area in a municipality. The above-described principles for HP measures [9] were applied during the planning and implementation of a recreational greenspace area in a four-year innovation and research project.

\subsection{Research Context (Case)}

The described case centers around the collaboration process linked to the establishment of a new local greenspace recreational area as a HP measure. The establishment of this recreational area was part of a four-year innovation and research project carried out in collaboration between the municipality, regional authorities, and research. During the project period, researchers closely followed the processes linked to developing, planning, and implementing the recreational area by applying a participatory action approach $[20,30,31]$.

A multi-sectoral project group, composed of representatives for the municipality (health, culture, environmental planning, school, and culture), the regional authority (County Council), and researchers was established. The multi-sectoral project group was responsible for outlining the collaboration processes linked to the development and establishment of the recreational area, and follow-up on inputs from the various activities. How the collaboration would be carried out in detail was not decided before-hand, instead, specific activities were included and planned based on inputs and experiences during 
collaboration. This ensures that processes as well as outcomes are developed locally and through collaboration activities. Other responsibilities within the multi-sectoral project group were to ensure that activities and goals also were in line with the above-described principles for HP.

The participatory action approach $[20,30,31]$ applied enabled researchers to gain deep insights into the activities and contextual factors influencing the collaboration as well as outcomes. Activities included project group meetings, public meetings, a Search Conference $[27,32]$ as well as interviews and focus-groups with municipal actors.

During the collaboration process and the above-described activities, several documents and other written material was produced. To gain an overview about how the five HP principles informed and guided activities, we applied a document analysis $[22,33]$ on this written material, describing the processes and how they were shaped during collaboration. To be included into this study, a written document had to (a) be produced in the context of the described project and (b) had implications for the further process during the project.

\subsection{Procedures and Data Sources}

Given the complex nature of the study aim, this case study uses available project data relevant to the study to explore possible pathways, unexpected consequences, and barriers in applying principles of health promotion when implementing a HP measure. As illustrated in Table 1 below, and according to our criteria, to include all written material that was produced during the collaboration process and had relevance for further processes, our data material included several types of documents (compare Table 1), which are linked to the collaboration process in different ways.

Table 1. Project activities and documents (type and number) produced during the four-year project period utilized as a basis for analyses.

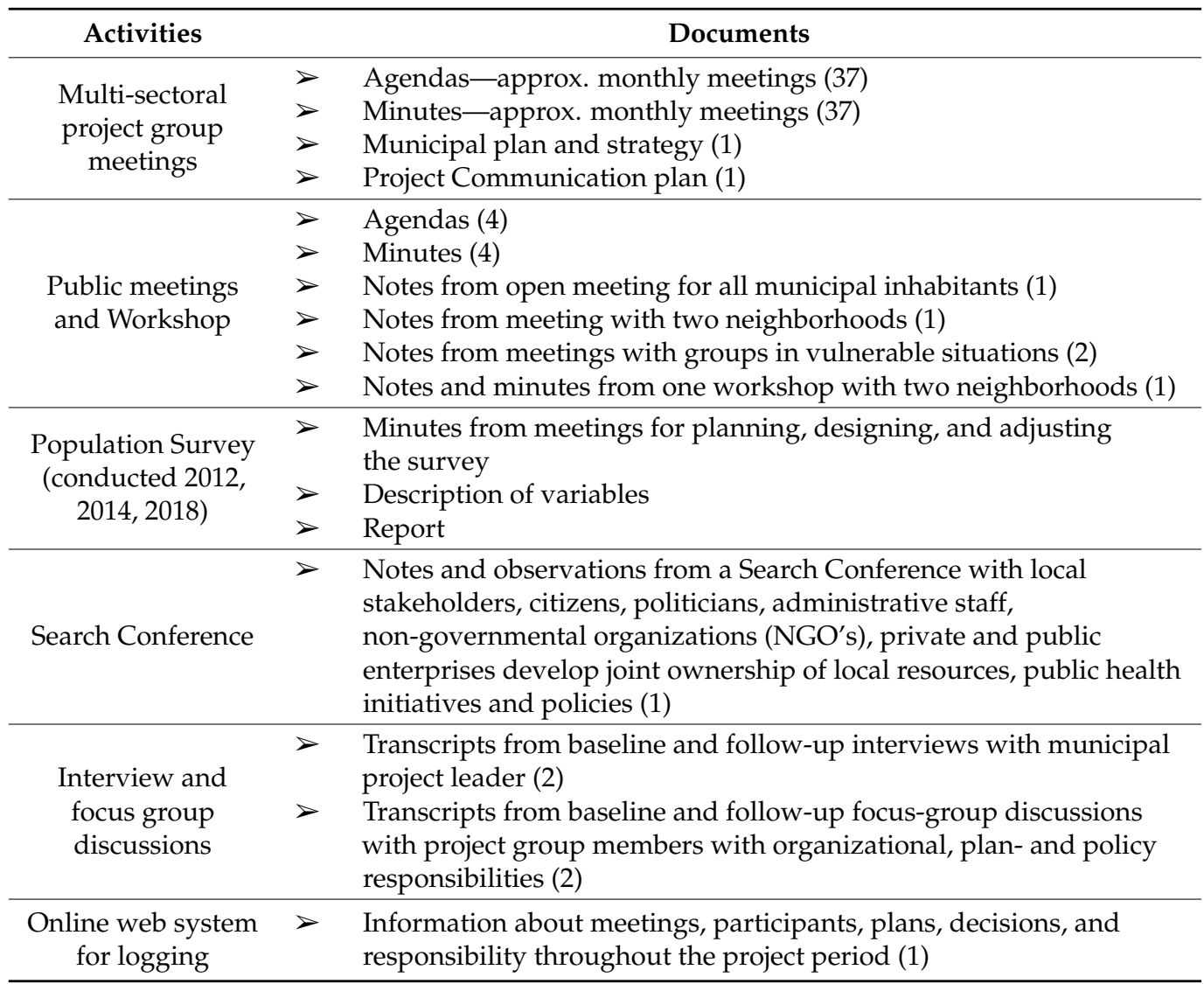




\subsection{Preparing Analysis}

The documents included were organized in seven categories: (1) formal documents such as municipal plans and strategies, (2) minutes and notes from formal and informal multisectoral project group meetings, (3) minutes and notes from public meetings and Workshop, (4) notes and participatory observations from a Search Conference, (5) population survey, (6) available data from stakeholder interviews and focus group discussions, and (7) notes from Log.

Below, we unravel how information from different types of documents was (a) applied to inform the process and (b) handled during data analysis.

\section{(1) Formal documents}

Available municipal documents, such as municipal strategies, policies, action and communication plans, and evidence of governance arrangements, represent part of the municipal context in which HP measures are developed. They define goals and strategies, describe roles and responsibilities, and play a major role in internal distribution of resources and attention $[12,13,15]$. Thus, they represent the conditions in which the HP measure is established. However, during the project phase, emerging insights and new strategic approaches were deliberately fed into new strategic plans to enhance conditions for HP in the municipality. Thus, strategic plans that were formed during the project period give pinpoints towards outcomes, e.g., if and how a broad health concept or participatory approaches are anchored in the strategic plans of the municipality.

(2) Minutes and notes from formal and informal multi-sectoral meetings

Notes, taken systematically during formal and informal project group meetings, as well as agendas and minutes from projects meetings within the municipality were included to provide further insight into the implementation process and how HP principles were applied to structure and evaluate collaboration processes. As the project group was responsible for facilitating for participatory and collaborative processes, these were crucial for following up on inputs and outlining the next steps continuously throughout the four-year period. Accordingly, during analysis, these documents provided insights into how inputs were followed up and, especially, how later activities were anchored in both emerging local insights on the one hand, and the overarching HP principles on the other hand.

\section{(3) Minutes and notes from public meetings and Workshop}

Throughout the process, public meetings and workshops were conducted in the municipality, as well as locally in neighborhoods situated near the developing recreational area. These were an integrated part of the collaboration process and served a dual function: on the one hand, inform inhabitants about the ongoing process, on the other hand, to gather inputs from inhabitants and engage in joined learning activities that, in turn, influenced both the outcome and the process itself.

Researchers followed these meetings, applying a participatory observation strategy. Participatory observation can provide rich data on decision-making, management processes, and communication $[20,30,31]$. Data from public meetings thus includes both minutes, as well as notes taken by researchers during the observation. During analysis, minutes were treated as "outcomes" of these meetings, representing deliberate inputs to inform further processes and the outcome. Observational notes, on the other hand, provide insights into discussions and interactions, and they provide information about how these inputs were negotiated, including how they related to the overarching HP principles.

\section{(4) Notes and participatory observations from a Search Conference}

One distinct form of workshop, a Search Conference, was conducted early in the project period and played a major part in defining the outcome of the project: it was during the Search Conference that the idea of this specific recreational area was developed and decided upon. A Search Conference describes a method for inclusive decision-making and coproduction of knowledge $[27,32]$. The research team conducted participatory observation 
during the two-day conference. Observations and notes from the Search Conference are used in this case study to (a) describe applied methods during the conference, (b) assess if and how contributions from the conference informed and shaped the subsequent implementation process, and (c) discuss how this contributed to realize the above-described principles for health promotion [9].

\section{(5) Population Survey}

In the early stages of the collaboration process, the need for more in-depth local knowledge about health-relevant factors emerged. To gather this information, a population survey was developed and conducted in co-operation between the municipality and research, combining assessments of local social, environmental, and organizational features with scientifically valid measures of health and well-being [34,35]. During the project period, three waves of the survey were conducted. Results from the first wave represented the baseline for the four-year project, and defined crucial needs, wishes, and target groups in the local context. Waves 2 and 3 were applied to track changes at the population-level, but also, to specifically, measure satisfaction with the developed area in respect to accessibility, quality, and frequency-of-use. The population survey thereby made crucial contributions to define the developed measure, as well as to evaluate how it was received by the population.

Minutes from meetings where the survey was planned and variables-of-interest were defined, as well as description of included variables, and utilized in analysis, as they illustrate how "health" and "health relevant factors" were defined and identified during the initial phase of collaboration. Moreover, findings from scientific reports $[24,35]$ are included in analysis. They provide pinpoints towards how the measure was anchored and evaluated in the general population and are thereby linked to participatory approaches.

(6) Available data from stakeholder interviews and focus group discussions

Focus group discussions and in-depth interviews are vital for exploring opinions, attitudes, experiences, and wishes among stakeholders [22,36]. While the multi-sectoral project group was involved in a variety of activities linked directly to gathering knowledge and facilitating for co-operation and community involvement, inputs from these processes were followed-up on higher levels, such as the chief municipal executive level. How participatory approaches and collaboration at lower levels is followed up and supported by the municipality is a crucial component of collaboration, and it influences whether a measure works in line with intentions.

However, as the project group had no access to these processes directly, interviews and focus group discussions with public health leaders/coordinators were used to generate further insights into municipal policy and plan processes, including implementation of the local recreation area. Moreover, it provided insights into how the implementation process was experienced by individuals and communities on the one hand, and implementers and public health leaders on the other hand. Moreover, interviews were conducted during the project period and could, thereby, influence subsequent processes, especially with respect to how to address and facilitate for multi-sector collaboration and following up on decisions at higher levels. They do, thereby, also provide crucial insights into facilitators and barriers for developing and implementing HP measures in the local community, as well as how the five overarching principles were applied to guide decisions and inform processes linked to contextual factors (in the wider municipality).

\section{(7) Notes from Log}

The local multi-sectoral project group established an online web system for keeping a log throughout the project period. The log included information about meetings, participants, plans, decisions, and responsibility, and it does, thereby, provide a detailed overview about activities in their chronological order. Moreover, log data included contextual information, as well as information on collaboration with external partners, and how these influenced the development of the recreational area. Thereby, the log gave valuable 
insight into facilitators and obstacles related to each step of the municipal planning and implementation process.

\subsection{Data Analyses}

Document analyses, proven useful within HP research, especially when trying to obtain insight into an activity or approach [22,33], were conducted to provide a deeper understanding of barriers and facilitators to the realization of the HP principles [9] at the municipal level.

Consistent with the approach developed by Yin (2009) [22], understandings gained from these multiple data sources were analyzed in an in-depth manner and then synthesized. By making use of a deductive oriented approach, each data source was analyzed to provide distinct understandings on how the above-presented principles for health promotion informed actions and activities and informed decisions during implementation (compare section "preparing data analysis" for a detailed description of these understandings) $[22,33]$. After having gained an understanding of how the various data sources informed the process on the one hand, and the research objectives on the other hand, we applied an inductive approach to explore the role of the HP principles in this process. Data was systematized in accordance with the five principles and how we understood them (compare Section 1.1). More specific lines-of-analysis included describing how the principles were applied, to choose and design collaboration activities and shape the overall focus, identifying possible barriers for applying the principles, and start outlining how applying the principles contributed to the shaping of the specific activities and decisions $[33,36]$.

\subsection{Synthesizing Emerging Findings}

After analyzing each data source in depth, and developing an understanding how the specific activities and decisions related to the overall principles [9], we synthesized information from each source to develop an overall picture of how the five HP principles informed the overall process. To do so, we tried to outline and "track" how the specific principles became visible across specific actions, activities, and decisions, and explored how they work together to shape the overall process and contribute to outcomes. Prior evaluations of the local recreation area were applied to measure "successful" implementation of the measure, whether it worked in line with the established goals, and to discuss the application of the principles in relation to the evaluation [21,24,34].

\section{Results and Discussion}

In the following, we utilize the broad data to describe and discuss how these five HP principles [9] were translated into actions and activities and discuss how applying these principles contributed to structure the collaboration processes linked to the implementation of a local recreation area. More specifically, we describe and discuss how the principles (1) guided focus of attention and helped to design approaches, (2) guided collaboration and activities during development and implementation processes of the HP measure, and (3) contributed to develop locally grounded HP measures.

Below, we present our findings by according to these levels-of-analysis. We start with giving a short description of how the principle guided actions and activities during the process. Then, we discuss how the specific principle contributed to shape the overall process and discuss potential barriers for, and benefits of, applying the specific principle. Last, we synthesize our findings and try to start outlining how applying the five principles contributed to anchor the locally grounded measure in the overarching principles for HP.

\subsection{A Broad and Positive Health Concept}

\subsubsection{Description of Actions and Activities}

Findings from the document analyses show that the HP principle of applying a broad and positive health concept and the new public health act in Norway [29] guided the development of the municipality long-term governance plan strategy. A holistic under- 
standing of health, a wellbeing focus, and an appreciation of close connections to linked agendas such as equity and sustainability, was anchored in the emerging plan strategy. This was done to establish a common ground that enabled stakeholders to identify reliable perspectives and thereby increase support politically, administratively, and across sectors (health, education, environment planning, and culture). Among other activities, did the broad health concept inform the development of a recurrent municipal survey on population health and wellbeing, including positive health indicators and the residents' wishes and needs [34,35]. The population survey data was used as a supplement to traditional municipal health data on disease development in planning and decision-making related to population health in general and development of the local recreation area specifically.

\subsubsection{Discussion}

As health promotion actions needs to respond to complex health issues that have multiple interrelated determinants, it is vital to understand the continuum of values and principles evident in health promotion actions from those associated with holistic, ecological, salutogenic health promotion $[2,7,9,12,23,37]$. Developing extensive broad knowledge about positive health indicators, the status of health and well-being in the municipality, and combining this with inhabitants' feedback on what needed improvement in the municipality, turned out to be an important facilitating factor of the implementation process.

Applying a broad and positive health-concept also enabled stakeholders to explore their specific contributions within the established common ground, e.g., to identify healthrelevant resources and processes across the spatial domains of the municipality. A key factor for success was to anchor the broad positive health concept politically and administratively in the overall municipal plan strategy, thereby placing responsibility for promoting population health across sectors and highlighting the role of political and administrative stakeholders. This finding supports the growing consensus that health is political, and health issues need to be brought into the political arena to advance population health $[8,23,25,38-40]$. It might also be linked to the recognition that health determinants depend on political action and the understanding health as a critical dimension of human rights and citizenship $[8,23,25,38-40]$. Securing political support for a broad and positive health concept can also potentially improve awareness about the underlying issues being addressed (e.g., health equity) $[8,12,25,38-40]$.

As such, the principle of a broad health concept in HP [9] guided the implementation of the greenspace recreation area by playing a major role in establishing a common ground; engaging in joined learning activities, centering on how health can be addressed from various angles, and defining roles and responsibilities. Moreover, starting with a broad and open definition of health, facilitated for the incorporation of various local and sector-specific aspects into the shared understanding of "health" as the overarching goal. Engaging in an open-ended dialog about what health is and how it can be promoted in the local context thereby emerged as a beneficial strategy to ensure a broad definition, and a good starting point, for involving stakeholders into the implementation process.

\subsection{Participation and Involvement of Key Stakeholders}

\subsubsection{Description of Actions and Activities}

Findings from the document analyses validate that the development of the local recreation area was firmly anchored in the Norwegian Public Health Act [29], which demands long-term planning, proactivity, and close interaction across different sectors, levels of management, and fields of expertise. By establishing a multi-sectoral project group, active involvement and commitment from stakeholders representing various municipal departments, institutions, and policymaking groups, as well as citizens throughout the implementation process, was facilitated and ensured. Findings indicate that, by making use of new formal and informal structures for cooperation and participation such as e.g., a Search Conference methodology [27,32], regular meetings, shared communication platform, public meetings, and participation in joint activities, key stakeholders were 
involved with designated roles and responsibilities. The development of the recreation area, originating from evidence and inhabitants' wishes (HP population survey), was anchored amongst property owners in the nearby residential area, local politicians, local businesses, and inhabitants. Early on, the multi-sectoral project group also established a communication plan, where the messages, target groups, communication channels, and the timing of various communication events were specified. Moreover, the association of local history enthusiasts was engaged to design informative boards placed at the recreation area, other groups made boards about the local flora and fauna, and a local group of senior men volunteered to contribute to the deforestation of the planned recreation area. As such, findings indicate that significant participation and involvement of key stakeholders contributed positively to the implementation of the local recreation area.

\subsubsection{Discussion}

For multi-sectoral initiatives to succeed, findings demonstrate that a lot of effort was put into fostering good relations among all key stakeholders. One important local condition was the Norwegian Health Act, [29] which emphasizes the importance of involvement in public health work and thereby justifies using time and resources on such activities. Amongst the actions needed to cultivate a supportive context were frequent formal and informal meetings, which helped to establish a common understanding amongst stakeholders of the overall mission and specific objectives of the local recreation area development [21]. Established formal and informal structures for cooperation and a shared history of previous collaboration were also found as important process facilitating factors, since they fostered communication, a common understanding, and a sense of ownership among stakeholders. Further, findings also indicate that collaboration among stakeholders resulted in additional sources of cooperation, as stakeholders introduced their partners to the initiative and, in turn, broadened the initiative's reach. Collaboration between stakeholders and representatives from various municipal departments and institutions, also allowed the local area development to attract attention from regional and national authorities, such as the Ministry of environment.

Obstacles for participation and involvement occurred with respect to raising motivation, time, and resources among stakeholders. While most agreed that "promoting population health" is a valid overarching goal, the data indicated that not all stakeholders could see how and why they should contribute to achieve this on top of their "regular" responsibilities. Engaging in joined efforts could sometimes be perceived as working to realize other's goals, which could draw resources from other, more sector-specific issues. Translating the overarching goal into more specific ambitions for the involved stakeholders was recognized as a crucial activity, which was partly done while negotiating the broad health-definition as described above. Anchoring and translating overarching goals into sector-specific aims thereby emerged as a favorable condition for raising motivation and resources among stakeholders. Moreover, findings indicated that joined activities and regular meeting places facilitated relationships among stakeholders that were characterized by mutual trust, respect, and acknowledgement of fields-of-expertise.

Such results indicate that multi-sectoral, collaborative initiatives need to dedicate time and resources to establishing trust and committed relationships among stakeholders. Commitment to such collaboration processes is closely linked to perceptions of making "real" contributions and participating in shaping outcomes and approaches. According to process interviews and focus groups, stakeholders did perceive their participation in the implementation process as "making a difference", as well as personally rewarding. Applying the HP principle of participation and involvement of key stakeholders [9], comprising shared understanding of the challenges as well as development of trust, ownership, shared ethics, and goals among those involved, was found crucial for successful implementation. However, a highly complex measure, as in this case, also requires an updated overview of the population health and impact factors, anchoring in plans, as well as new skills and methods for selection and implementation [10,24]. 


\subsection{Build Action and Action Competence by Involving and Empowering Target Groups \\ 3.3.1. Description of Actions and Activities}

Findings from the document analyses show that the HP principle of building action and action competence by involving and empowering target groups $[2,9,24]$ was emphasized by inviting local stakeholders, such as inhabitants, politicians, administrative staff, and non-governmental organizations (NGOs) to a public meeting in which results from the population survey were disseminated and followed up by a Search Conference [25,26]. Corresponding to the target groups, school children, and staff from the local school, as well as representatives for local user organizations were especially invited to participate. A concrete plan for the development of a local recreation area was developed during a Search Conference $[27,31]$. The Search Conference methodology is a participatory mixed strategy using both bottom-up and top-down approaches [12,26,27], which is found useful for setting new policy directions, strategies, and actions in any sector, public or private.

Results from the document analyses also suggest that the stakeholders were assigned with specific tasks and roles for developing the local recreation area; several sectors from the municipal administration (health, planning, school, environment, culture), representatives from various user organizations (i.e., the youth organization, the senior council, organizations for physical and mental disabilities), the Norwegian Railway Agency, and the chief municipal executive ensured progress of the implementation in close collaboration with the project group. A local entrepreneur was contracted to build the local recreation area, while other parts of the maintenance was assigned to a local group of volunteers.

To build action competence, all employees working on community planning in the municipality participated in a project management course, in which they reported obtained skills on how to work more systematically and across sectors and professional fields. Moreover, the data show that local public meetings were conducted to gather inputs and offer opportunities for joined learning and participation in shaping the final form of the recreational area.

\subsubsection{Discussion}

Participation in collective actions for healthy and sustainable local communities can contribute to empowerment through increased knowledge and skills, increased access to resources, and improved opportunities for people to come together and establish social networks and trust $[11,23,27,38,39]$. Prior evaluations (population survey) indicated an increase in satisfaction, with opportunities to participate in decision-making processes [33]. Findings from the interviews and focus group transcripts also emphasized the importance of including target groups and volunteers to ensure that the measure meets the needs and wants of citizens in the local community. Being directly involved in shaping the outcomes of the initiative contributed to empowerment especially for target groups, provided participants with a sense of ownership over the initiative and had positive implications for the participants' sense of mastery over their lives and their health and well-being. Engagement with the area and participation in the daily maintenance also ensured enduring opportunities for learning, contributing, and shaping outcomes in the local context. Another small, but significant, facilitating factor found was the skills upgrade and opportunities for joined learning provided to the project group. By participating in a project management course, implementers reported obtaining skills on how to work more systematically and across sectors and professional fields.

Obstacles for building action competence and empowering target groups were found to be mainly linked to recruitment of target groups and considerations around valid channels and methods for recruitment. Even if broad methods for involvement were applied, we cannot be sure that the multi-sectoral project group succeed in including people in vulnerable positions who are often less prone to participate in this kind of activities [21,24]. In line with the HP principle 'build action and action competence by involving and empowering target groups', findings indicate that the broad involvement of target groups, and the open and transparent process, created a sense of ownership 
and positive feelings towards the development of the local recreation area and directly contributed to empowerment by providing a channel-of-influence for inhabitants.

\subsection{A Setting Perspective}

\subsubsection{Description of Actions and Activities}

The setting approach $[9,10,17-19]$ is a relevant conceptual framework for developing HP measures for sustainable impact in community health promotion. In line with a setting approach $[9,10,17-19]$, findings indicate that community participation, partnership, empowerment, and equity were emphasized at all stages of the implementation process, and the structure of collaboration among local stakeholders directly affected how the initiative was implemented. Local conditions proved to play a major role in defining both challenges, strategies, and available resources. Conducting in-depth document analysis to assess how health relevant goals are a described in the various plans and goals was therefore an important step to explore the boundaries, the internal rules and the values which could impact the implementation process. Moreover, analyzing sector-specific plans helped to define roles and responsibilities, and it emphasized the importance of anchoring health-relevant goals in specific, as well as overarching, strategic documents.

Next, applying a setting-approach $[9,10,17-19]$ helped to identify challenges as well as identify central stakeholders for involvement such as property owners, railway agency, and local groups of volunteers. A detailed analysis of the context uncovered e.g., timing, costs, safety requirements, and soil contamination as contextual factors that influenced the implementation of the recreation area. Applying a setting-approach also contributed to extending the aims for the measure, and especially, defining the desired long-term developments within the setting which the specific area could contribute to. Thus, ambitions to develop a local recreation area that was flexible and responsive to specific local and changing conditions, and a research process that can contribute to empowerment and locally grounded solutions, were established because of considerations around how the specific measure can contribute to overarching local development goals.

\subsubsection{Discussion}

As settings approach focuses on the physical, organizational, and social contexts in which people are found $[9,10,17-19]$, a better understanding of settings will potentially improve the probability of successful implementation of HP measures. This framework of settings goes beyond the notion of adjusting a standard intervention protocol to "fit" a particular setting [19]. Instead, as shown in this case study, it involves a detailed analysis of the context. Analysis of the setting, including its internal values, goals, and strategies at an early stage, was proven helpful in organizing for action and optimizing the likelihood of successful implementation. It also created valuable opportunities for capacity building within the setting, as it emphasized the complex nature of the implementation process and highlighted the importance of collaboration and joined actions. A key factor found in this regard was that health-relevant goals were largely already implemented into local strategic documents, even if they were not always sufficiently translated into sector-specific goals and recommendations for practice. Thus, health was established as a core value within the municipal setting, which was a beneficial condition for raising motivation and resources to address the issue within the setting.

\subsection{Equity in Health}

\subsubsection{Description of Actions and Activities}

Health equity is manifested through differences in health outcomes and is linked to inequity on the social determinants for health $[40,41]$. This highlights the importance of tackling inequity through addressing the determinants of health, including opportunities to participate in society-development, and being able to define and gain acceptance for one's own needs and wishes when it comes to HP measures. Findings indicate that an equity perspective was actively used during all steps-of-implementation of the local recreational 
area, by assessing potential benefits and hazards for people in vulnerable situations before conducting each step-of-implementation.

A strong focus on involvement, and especially involving target groups and people in vulnerable situations, is at the heart of promoting health equity, as this simultaneously offers opportunities to build competence, and to contribute to develop resources and processes in line with the ideas and challenges of these groups. Thus, findings show that efforts were undertaken to mobilize especially vulnerable groups to participate in the activities linked to the implementation of the recreational area, especially the Search Conference and open meetings. Predictable processes ensured that their contributions were used actively during implementation.

\subsubsection{Discussion}

Health equity can be addressed through a variety of methods. In line with previous studies $[21,23,28,39,41]$, findings from this study show that involving groups and people that feel marginalized in society, in this kind of implementation process with visible outcomes, can contribute to perceptions of ownership, feeling valued and mastery, and can reinforce belonging to the place and the local social community, which are important aspects of health. Moreover, including target groups in the implementation of amenities can increase perceived "fit" and satisfaction with, as well as use of, these amenities. Previous evaluations show that the recreational area is used frequently, and people with low income or disabilities are over-represented as users. Thus, the area potentially plays an important role in levelling-out health inequity [21].

The main challenge identified in this regard is, as pointed out earlier, to recruit among people in vulnerable positions, who are often less prone to participate in this kind of activity. Moreover, participation might be spoiled through the way data is gathered, how questions are asked, and insecurity around if participation really can lead to change and improvement of own living conditions. Thus, predictable processes and an atmosphere of trust emerged as key factors for participation among vulnerable groups.

\subsection{Applying the Principles for HP to Structure Implementation Processes-Challenges and Opportunities}

This case study explored how the five HP principles [9] can (1) guide focus of attention and help to design approaches, (2) guide collaboration processes (development, implementation processes) and activities, and (3) contribute to developing locally grounded measures that contribute to local HP.

Applying the above-presented principles for HP guided actions, and focus-of-attention throughout the process of implementing a local recreation area, contributed thereby to keeping a red thread and increasing consistency during the four-year process. More specifically, the principles guide actions towards recognizing the municipality as a setting, identifying stakeholders, and highlighting the importance of involving actors from all relevant sectors and levels throughout the whole implementation process, which is in line with a setting approach $[10,19]$.

Still, during the planning and conduct of the implementation process, we experienced that the inter-connected nature of these principles yields some obstacles in terms of translating principles into actions. For example, it might be hard to distinguish activities linked to "participation and involvement" from activities linked to "built action competence through involvement"; both imply inclusive approaches, which are also tightly linked to the principle of health equity. Even if all these principles offer valid perspectives on what to achieve with activities, recommendations on how to ensure that activities are in line with the five principles; what can be done to ensure the principles through municipal practice would be valuable? For example, while the principle about involvement implies cross-sector collaboration, it falls short on providing knowledge on how to achieve such collaboration and how to address the inherent challenges in such approaches, such as how 
to raise motivation among stakeholders, or to find and activate resources to participate in the collaboration.

This is partly linked to the principles themselves describing a variety of factors, from defining an overall understanding (settings approach) to implying quite specific activities ("stakeholder involvement"). How the principles were applied during the process, and where and how they became visible throughout analysis, varied accordingly. While for example applying a settings perspective contributed to define the context for this study; identify stakeholders and arenas and establish a common understanding about how this work together to create a local context; did this perspective not contribute extensively to defining specific actions? Stakeholder involvement and participatory approaches, on the other hand, suggested a line-of-activities and provides pinpoints towards how inputs should be handled during the process. However, during synthesizing findings and outlining emerging understandings, the settings approach and its implications again emerged as a crucial starting point, emphasizing the importance of everyday settings.

All in all, the importance of specific principles could vary throughout the process. However, principles that were not applied "active" at a certain point did still inform ongoing decisions; for example, include joined learning activities to ensure empowerment while exploring the broad health concept. Applying the principles contributed to establish processes that led to the development of a measure that was both locally grounded, and in line with the principles for HP.

Moreover, focus group discussions and individual interviews pointed out some key factors for success which are not directly captured or expressed in the above-discussed principles. For example, our findings suggest that an atmosphere of trust, mutual respect and predictable processes were crucial strategies to recruit especially people in vulnerable situations to participate in the implementation and raise motivation among collaborators [11]. One beneficial strategy to achieve this seemed to be to facilitate joining and mutual learning among participants. Moreover, grounding approaches in evidence and providing expert knowledge seemed to contribute to empower stakeholders by building competence and making them safe with respect to their roles and responsibilities. The role of collaborative decision-making, agreement of objectives and goals, local planning, and action, building and maintaining trust, and trained and knowledgeable implementers emerged as facilitating factors for supporting health promoting policy development and HP program implementation at local levels, as shown in previous studies as well $[27,38,39]$.

Demands for evidence-based HP approaches and broad health knowledge is anchored in the Norwegian Public Health Act [29], which emerged as a key factor for successful implementation as well as for empowering stakeholders. The need to ground approaches in broad context specific knowledge are not sufficiently addressed in the five principles. Still, anchoring a broad health concept, as well as goals on health promotion and equity in the overarching, as well as the sector-specific plans and strategic documents was essential for successful implementation through raising motivation, releasing resources, and ensuring continuity despite political shift. Moreover, broad involvement and, especially, political and administrative support ensured that HP efforts continued to be a central part of municipal development even after the specific measure was implemented.

This points, perhaps, to one of the most crucial factors for reaching long-term population health goals, which was to move HP efforts from project-based methods to systematic, ongoing HP approaches incorporated in municipal development and every-day work within the settings of their everyday life [2].

All together, these results show that the five principles of health promotion offer a very promising starting point and a guidance towards improving HP action at the local level.

\subsection{Methodological Limitations}

As in all research, consideration must be given to validity and reliability $[22,33,36]$ There are some limitations related to the nature of a single case study design. However, a formal case study protocol was developed to provide required reliability. The current study 
used data from multiple written documents that had to (a) be produced in the context of the described project and (b) had implications for the further process during the project.

The rationale for synthesizing data from multiple sources was the triangulation of evidence. Triangulation increases the reliability of the data and the process of gathering it. However, one danger, associated with the analysis phase, is that each data source is treated independently and thus, the findings reported separately. As this is not the purpose of a case study, data from all sources were synthesized to ensure that the data were converged to understand the overall case, not the various parts of the case, or the contributing factors that influence the case. Thus, even during data-analysis, the settings-perspective became visible.

Our strategy, to ensure that we remained true to the original case, was to work together with the analysis and to provide feedback on the ability to integrate the data sources to answer the study aim. Instead of analyzing data from each source separately, we combined data from different sources to illuminate sub questions and focus areas related to the implementation of the local HP measure. However, to synthesize our knowledge across these sub-questions, we synthesized and integrated all available project data to investigate how the five HP principles guided actions and focus-of-attention throughout the entire process of implementing a local community HP measure.

Although there is always a risk of under- or overestimating the relevance and influence of the local context when analyzing data, we believe that we identified some key elements for successful implementation, which could potentially support and improve the applicability of the HP principles. The potential for over-reliance on document as evidence in case studies has also been criticized [22]. To avoid incorrect data being used, the validity of the documents was carefully reviewed by an experienced investigator and further processed in the research group.

Although a single case study based on written documents makes it difficult to reach a generalizing conclusion, we believe this study contribute valuable knowledge to the discussion on how HP principles can be applied to structure collaboration processes for implementing HP measures and policies in local communities. Thus, we argue for further investigation in relation to elements that we believe should be captured by the HP principles.

\section{Conclusions}

The HP principles guided actions and focus-of-attention throughout the planning and implementation process of the local recreation area and contributed, thereby, to keeping a red thread and increase consistency during the entire process. Investment in time and effort, into trust- and capacity-building activities, at the beginning of the implementation process facilitated later activities. Of special importance was the broad involvement of stakeholders and the anchoring of overarching, as well as specific, HP goals in the municipal strategic documents to ensure political commitment, ownership, and adequate resources. Although the HP principles guided the local recreation area development in direction from project organization to systematic day-to-day work for work, direction on how to apply or achieve the HP principles should be further explored and described as implementation processes are highly context dependent.

Author Contributions: Conceptualization, M.L. and R.E.K.M.; methodology, M.L. and R.E.K.M.; formal analyzes, M.L. and R.E.K.M.; investigation, M.L.; resources, M.L.; data curation, M.L. and R.E.K.M.; writing-original draft preparation, M.L. and R.E.K.M.; writing-review and editing, M.L. and R.E.K.M.; project administration, M.L. All authors have read and agreed to the published version of the manuscript.

Funding: This research was funded by Regional Research Funds in Norway project no. ES 469747/209033.

Institutional Review Board Statement: The study was conducted according to the guidelines of the Declaration of Helsinki.

Informed Consent Statement: Not applicable. 
Data Availability Statement: Not applicable.

Acknowledgments: The authors would like to thank the project group for their contribution.

Conflicts of Interest: The authors declare no conflict of interest.

\section{References}

1. Declaration of Alma-Ata. In Proceedings of the International Conference on Primary Health Care, Alma-Ata, USSR, Alma Ata, Kazakhstan, 6-12 September 1977; World Health Organization: Geneva, Switzerland, 1978. Available online: http:/ /www.who. int/publications/almaata_declaration_en.pdf (accessed on 19 September 2021).

2. World Health Organization. The Ottawa Charter for Health Promotion: First International Conference on Health Promotion, Ottawa, 21 November 1986; WHO: Geneva, Switzerland, 1986.

3. Health 2020: A European Policy Framework Supporting Action across Government and Society for Health and Well-Being; EUR/RC62/9; WHO Regional Office for Europe: Copenhagen, Denmark, 2013. Available online: http://www.euro.who.int/en/aboutus/governance/regional-committee-for-europe/past-sessions/sixty-second-session/documentation/working-documents / eurrc629-health-2020-a-europeanpolicy-framework-supporting-action-across-government-and-society-for-health-and-wellbeing (accessed on 19 September 2021).

4. Health in All Policies: Framework for Member State Action; World Health Organization: Geneva, Switzerland, 2013. Available online: http:/ / www.who.int/healthpromotion/conferences/8gchp/130509_hiap_framework_for_country_action_draft.pdf (accessed on 20 September 2021).

5. Helsinki statement on health in all policies. In Proceedings of the Eighth Global Conference on Health Promotion, Helsinki, Finland, 10-14 June 2013; World Health Organization: Geneva, Switzerland, 2013. Available online: http://www.who.int/ healthpromotion/conferences/8gchp/statement_2013/en/index1.html (accessed on 19 September 2021).

6. Potvin, L.; Jones, C.M. Twenty-five years after the Ottawa Charter: The critical role of health promotion for public health. MOJ Public Health 2011, 102, 244-248. [CrossRef]

7. Potvin, L.; Jourdan, D. Health promotion research has come of age! Structuring the field based on the practices of health promotion researchers. Glob. Health Promotion 2021, 1044077. [CrossRef] [PubMed]

8. Kickbusch, I.; Gleicher, D. Governance for Health in the 21st Century; World Health Organization: Geneva, Switzerland, 2012.

9. Grabowski, D.; Aagaard-Hansen, J.; Willaing, I.; Bruun Jensen, B. Principled Promotion of Health: Implementing Five Guiding Health Promotion Principles for Research-Based Prevention and Management of Diabetes. Societies 2017, 7, 10. [CrossRef]

10. Scriven, A. Health promotion principles and the settings approach: Introduction to part 1: Principles and practice in a settings approach. In Health Promotion Settings: Principles and Practice; Scriven, A., Hodgins, M., Eds.; Sage Publications: London, UK, 2012.

11. Lillefjell, M.; Magnus, E.; Knudtsen, M.S.; Wist, G.; Horghagen, S.; Espnes, G.A.; Maass, R.E.K.; Anthun, K.S. Governance for Public Health and Health Equity-The Tröndelag Model for Public Health Work. Scand. J. Public Health 2018, 46 (Suppl. 22), 37-47. [CrossRef] [PubMed]

12. Fosse, E. National objectives-local practice. Implementation of health promotion policies. In An Ecological Perspective on Health Promotion: Settings, Systems and Social Processes; Wold, B.B., Samdal, O., Eds.; Bentham e-Books: Sharjah, United Arab Emirates, 2012.

13. Green, J.; Tones, K.; Cross, R.; Woodall, J. Health Promotion: Planning and Strategies, 3rd ed.; Sage: Los Angeles, CA, USA, 2015.

14. Dooris, M. Holistic and sustainable health improvement: The contribution of the settings-based approach to health promotion. Perspect. Public Health 2009, 129, 29-36. [CrossRef] [PubMed]

15. Poland, B.; Krupa, G.; McCall, D. Settings for Health Promotion: An Analytic Framework to Guide Intervention Design and Implementation Health Promotion Practice. Soc. Public Health Educ. 2009, 10, 505-516. [CrossRef]

16. Minary, L.; Alla, F.; Cambon, L.; Kivits, J.; Potvin, L. Addressing complexity in population health intervention research: The context/intervention interface. J. Epidemiol. Community Health 2019, 72, 319-323. [CrossRef] [PubMed]

17. Hodgins, M.; Griffiths, J. A whole systems approach to working in settings. In Health Promotions Settings: Principles and Practice; Scriven, A., Hodgins, M., Eds.; Sage Publications: London, UK, 2012.

18. Hodgins, M.; Scriven, A. Health promotion settings: Introduction to part 2: Healthy settings. In Health Promotion Settings: Principles and Practice; Scriven, A., Hodgins, M., Eds.; Sage Publications: London, UK, 2012.

19. Bloch, P.; Toft, U.; Reinbach, H.C.; Clausen, L.T.; Mikkelsen, B.E.; Poulsen, K.; Jensen, B.B. Revitalizing the setting approachsupersettings for sustainable impact in community health promotion. Int. J. Behav. Nutr. Phys. Activity. 2014, 11, 1-15. [CrossRef] [PubMed]

20. Isreal, B.A.; Schultz, A.J.; Parker, E.A.; Becker, A.B.; Allen, A.J.; Guzman, R.; Lichtenstein, R.; Wallerstein, N. Critical Issues in Developing and Following CBPR Principles. Community-Based Participatory Research for Health: From Process to Outcomes; Jossey-Bass: San Francisco, CA, USA, 2008.

21. Anthun, K.S.; Maass, R.E.K.; Hope, S.; Espnes, G.A.; Bell, R.; Khan, M.; Lillefjell, M. Addressing Inequity: Evaluation of an Intervention to Improve Accessability and Quality of a Green Space. Int. J. Environ. Res. Public Health 2019, 16, 5015. [CrossRef] [PubMed]

22. Yin, R.K. Case Study Research: Design and Methods, 4th ed.; SAGE Publications: Thousand Oaks, CA, USA, 2009. 
23. Maass, R.E.K.; Lindstrøm, B.; Lillefjell, M. Neighborhood-resources for the development of a strong SOC and the importance of understanding why and how resources work: A grounded theory approach. BMC Public Health 2017, 17, 1-13. [CrossRef] [PubMed]

24. Anthun, K.S.; Lillefjell, M.; Espnes, G.A.; Hope, S.; Maass, R.E.K.; Nguyen, C.; Sætermo, T.F.; Morris, G. INHERIT: Implementing Triple-Win Case Studies for Living, Moving and Consuming that Encourage Behavioural Change, Protect the Environment, and Promote Health and Health Equity; EuroHealthNet: Brussels, Belgium, 2019. Available online: https://www.inherit.eu/implementingtriple-win-case-studies / (accessed on 19 September 2021).

25. Brown, C.; Harrison, D.; Burns, H.; Ziglio, E. Governance for Health Equity: Taking forward the Equity Values and Goals of Health 2020 in the WHO European Region; Final Report; World Health Organization: Copenhagen, Denmark, 2014.

26. Arnstein, S. A ladder of citizen participation. AIP J. 1969, 35, 216-224. [CrossRef]

27. Magnus, E.; Knudtsen, M.S.; Wist, G.; Weiss, D.; Lillefjell, M. The search conference as a method in planning community health promotion actions. J. Public Health Res. 2016, 5, 60-67. [CrossRef] [PubMed]

28. Horghagen, S.; Magnus, E.; Anthun, K.S.; Knudtsen, M.S.; Wist, G.; Lillefjell, M. Involving citizens' occupation-based knowledge in public health planning: Why and how. J. Occup. Sci. 2017, 25, 1-12. [CrossRef]

29. The Norwegian Public Health Act; Helse- og omsorgsdepartementet: Oslo, Norway, 2012.

30. Baum, F.; MacDougall, C.; Smith, D. Participatory action research. J. Epidemiol. Community Health 2006, 60, 854. [CrossRef] [PubMed]

31. Von Heimburg, D.; Ness, O. (Eds.) Aksjonsforskning: Samskapt Kunnskap Som Endrer Liv Og Samfunn; Fagbokforlaget: Bergen, Norway, 2021.

32. Emery, M.; Purser, R.E. The Search Conference: A Powerful Method for Planning Organizational Change and Community Action; Jossey-Bass Inc. Pub.: San Francisco, CA, USA, 1996.

33. Gross, J.M.S. Document Analysis. In The SAGE Encyclopedia of Educational Research, Measurement, and Evaluation; SAGE Publications Inc.: New York, NY, USA, 2018.

34. Maass, R.E.K. The Neighborhood as a Salutogenic Setting. Ph.D. Thesis, NTNU, Trondheim, Norway, 2018.

35. Lillefjell, M.; Maass, R.; Espnes, G.A. Helse Og Livskvalitet I MALVIK Kommune 2012-LEV VEL. In Rapportserie Fra Senter for Helsefremmende Forskning HIST/NTNU; Rapport 2013/01; NTNU Trykk: Trondheim, Norway, 2013; ISBN 987-82-93158-15-8.

36. Malterud, K. Kvalitative Forskningsmetoder for Medisin Og Helsefag; Universitetsforlaget: Oslo, Norway, 2017.

37. Antonovsky, A. Unraveling the Mystery of Health-How People Manage Stress and Stay Well; Jossey-Bass: San Francisco, CA, USA, 1987.

38. Lillefjell, M.; Knudtsen, M.S.; Wist, G.; Ihlebæk, C. From knowledge to action in public health management. Experiences from a Norwegian context. Scand. J. Public Health 2013, 41, 771-777. [CrossRef] [PubMed]

39. Weiss, D.; Lillefjell, M.; Magnus, E. Facilitators for the development and implementation of health promoting policy and programs-a scoping review at the local community level. BMC Public Health 2016, 16, 140. [CrossRef] [PubMed]

40. Frohlich, K.L.; Potvin, L. Transcending the known in public health practice: The inequality paradox: Population approach and vulnerable populations. Am. J. Public Health 2008, 98, 216-221. [CrossRef] [PubMed]

41. Dahlgren, G.; Whitehead, M. The Dahlgren-Whitehead model of health determinants: 30 years on and still chasing rainbows. Public Health 2021, 199, 20-24. [CrossRef] [PubMed] 